\title{
Study on the Management Pattern of Wenzhou Family Enterprises under Traditional Chinese Thoughts and Ideas
}

\author{
Chunxiao $\mathrm{Li}^{1} \&$ Jiahui Yao ${ }^{1}$ \\ ${ }^{1}$ Shanghai University of Engineering Science, No.350, Xianxia Rd, Changning district, Shanghai 200336, China \\ Correspondence: Jiahui Yao, Shanghai University of Engineering Science, No.350, Xianxia Rd, Changning district, \\ Shanghai 200336, China
}

Received: May 11, 2017

Accepted: September 20, 2017

Online Published: October 10, 2017

doi:10.5430/jbar.v6n2p46

URL: https://doi.org/10.5430/jbar.v6n2p46

\begin{abstract}
This paper studies the management model of typical Chinese family from the perspective of Chinese thought history, and defines the ideological and industrial advantages of its special management mode. From the perspective view of human resources, capital investment and product development, how to transform and upgrade the family management mode are discussed so as to adapt to the enterprise development during the Internet era.
\end{abstract}

Keywords: Family enterprises, Ideas inheritance, Upgrade \& transformation

With China's reform and opening up the private economy has flourished, the vast majority of which are family enterprises; even in listed companies, the family enterprise also accounts for about half of the share. The family enterprise in Wenzhou is one of the typical models of Chinese family enterprises.

Wenzhou economic model has enjoyed popularity for a time during the period of China's reform and opening up, but after the 1990s, the imitative learning mode of Wenzhou enterprises has led to excessive competition within the industry, and the promulgation of the new labor law has significantly increased the labor costs of the low value-added manufacturing enterprises in Wenzhou as well. On the one hand, enterprises have invested a lot in fast profit-making industries, resulting in "empty" industry; on the other hand, the "usury" chain reaction caused by mutual guarantee among Wenzhou enterprises has broken the traditional affinity culture and acquaintance economy. However, the most unfortunate is that Wenzhou enterprises, known for its acuity and be the first in the world, have missed the golden developing period of the internet economy. The development of Wenzhou enterprises has entered a critical period of transformation and upgrading.

\section{Wenzhou Family Enterprise}

Wenzhou family enterprise is a kind of economy organization group consisting of the family, enterprise and ownership, which are mutually independent and overlap each other, under special political and cultural background of China's reform and opening up. In the Wenzhou economy, which started from family workshop or family unit, family enterprise has almost become the synonymous with the Wenzhou economic system.

\subsection{The Concept of Family Enterprise}

Family enterprise can be defined as a business organization whereby certain families own all or parts of the property, family rules integrate with enterprise systems, and family members keep on controlling over the long term. Family refers to the group consisting of all the relatives within the clan. They maintain close personal relationships with senior managers and retain the primary decision-making authority of senior management, especially in terms of financial policy, resources allocation and selection of senior staff.

\subsection{Causes of Wenzhou Family Enterprise}

Wenzhou has more people and less land, and traffic there is inconvenience, so leaving home to make a living has become a normal state. Wenzhou people always attach importance to kinship and local relations, the phenomenon that the family and fellow villagers join hand to engage in commercial trade and products production is widespread. As the family and the enterprise grow to coexist with each other, the family members enjoy high levels confidence to each other and they are earnest and responsible for work, and the decision-making is simple, thus forming a strong inherent cohesion to solve external problems, which has played a decisive role in the development of enterprises. 


\section{Wenzhou Family Enterprise Model and Traditional Chinese Thought}

Wenzhou is far away from the political and cultural center in history due to its remote location and inconvenient transportation, but it has successfully preserved the traditional Chinese culture and inherited the typical Chinese thoughts. We can see the significant features of Chinese thoughts from Wenzhou family enterprise model.

\subsection{Kinship-based Hierarchical Status Concept}

Chinese culture has always had a "family-centered kinship hierarchy", Chinese people view the hierarchy as the rule and the family extension as the source. The mainstream model of Wenzhou family enterprise succession still maintains the mode of "father-to-son" succession which is extrapolated from difference sequence pattern, and profit distribution fully embodies the Chinese people's thought "Inequality, not scarcity, that persecutes governors". For example, a WenZhou leather enterprise would rather choose an eldest son which is less capable to be the President of the company, but will not allow the daughter with excellent operating ability to assume the position. By the Kinship-based hierarchical status concept, within the family business, there will be recognition of consistency. However, the "equality" here is not "impartiality", it is the "equality" based on the principle of "ranking order". For example, the eldest son and the eldest grandson have preferential interests, married daughter and non-kinship daughter-in-law, etc. are not belong to the scope of "equality". But even in such seemingly unfair management model there still exists the concept of assisting the weak which is set for family proliferation or family reserves. For example, the whole family enterprises will support outstanding descendants, or help the weaker family members to achieve certain career base. Of course, the ranking and contributions of individual will also be considered during profit distribution.

\section{2 "Patriarchy-based" Family Management}

In Wenzhou family enterprise, ownership and management right are highly unified, the investor is the operator and the decision-maker is the management. The core management of the enterprise is usually the head of the family, who plans the development of the enterprise by taking the survival and development of the family enterprise as the core. Wenzhou enterprises are rooted in the traditional "family culture", which is connected with the state of the enterprise at startup in the late 1970s, at that time, most of Wenzhou enterprises are just family workshops, which have small scales and do not need higher level of management. Usually it is the father or the eldest son who shall arrange the internal division of the enterprise, male family members shall be responsible for external procurement and marketing and female family members take charge of internal financial and processing management; they may schedule corresponding positions according to kinship affinity and personal abilities, thus the enterprise tends to a flat management. They carry out conscious management within the enterprise through abiding by kinship-based family values, such as mutual aid, mutual benefit and trust. Family employees even include underage children, who will do certain part of work within their power as they know very well that the work will support their future growth.

Meanwhile, the traditional clansman concept and geographical culture in Wenzhou have formed a team-collaboration business model which takes family members as the core and the clansman as the basic force, thus a stable human resources system has been formed by centering on the kinship, geographical relationship and genetic relationship.

\section{3 "Moral-based" Contractual Financing Model}

In the traditional Chinese thoughts and ideas, the Chinese people take moral as the ultimate goals. The moral outlook of the Chinese concept "Soratani Orchids" requires people to constrain themselves by relying on the power of inner goodness only without external forces in the absence of anybody's attention. "Moral outlook" here refers to the rules obeyed by both the ethnic group and individuals, and the ethnic groups refer to the groups consisting of the clansman, neighbors, etc. based on the geographical culture. The "moral outlook" in Chinese culture has been extended to various fields, including the business field.

In the Wenzhou model, mutual loan and mutual aid between families are very common and have formed verbal contracts. The specific performance is as follows: When a family member matured into an adult plans to start a business, the family member who owns a business will provide an opportunity, like invite him/her to join the business or provide appropriate technologies; and other family members will jointly provide venture capital to help $\mathrm{him} / \mathrm{her}$ to start a business. At the same time, China's traditional credit contract has survived naturally in the form of "commercial contract", and funds needed for the production and sales process of Wenzhou small -and- medium-size enterprises are supported through the mode of owning the downstream, which has solved the financial problems for the small enterprises in the early stage, so as to make it survived successfully, but such mode has also left the hidden risk of chains of debt. In Wenzhou folk tradition, a year's debt must be repaid before the end of the Chinese lunar calendar; no matter whether there is any written evidence or not, once the creditor is going to die, the debtor must 
pay the debts to his/her descendants, etc. all of the aforementioned are typical manifestations of Chinese morality.

\section{Development Trend of Modern Family Enterprises}

This kind of family enterprise model developed based on the traditional Chinese thought mode has won moderate success, but its defects have emerged as well in the rapid development and transformation of society, especially during the Internet ear. With the changes in the core values of Confucian ethics and the impacts of multiculturalism from all over the world, Wenzhou traditional family enterprise culture and modern enterprise culture have interacted and merged and began to change and develop.

\section{1 "Quasi Family" Human Resources Management Model}

When the family management model is based on China's family planning, family enterprises are already desperately short of alternative position talents among family members; and the second generation of children's employment interests, competencies and many other factors have also lead to the result that the intergenerational inheritance in the mode of "father-to-son" succession is not attainable. In the survey of 100 Wenzhou family enterprises, the one child family accounted for 62 percent, within them, those who were not interested in the family business accounted 51 percent. Meanwhile, under the circumstances that the ownership, operation rights and management rights are centralized to one person, the motivation of core staff will be suppressed. Among the family members, those who share equity of $50 \%$ to $60 \%$ is $8 \%$; of 60 to $70 \%$ is $9 \%$; $8 \%$ of $70-80 \%$; Over 80 percent is $40 \%$. The proportion of some Wenzhou enterprises will be adjusted greatly during the listing process and after the listing.

In this case, the introduction of professional managers or the absorption of outstanding employees into the family enterprise have become the mainstream, through which the business owners and the employees that are not family members cultivate a kind of family affection based on the geographical and occupation relationships, and those employees have become the non-family family members, so as to form a "Quasi family". Introduce employees who have no blood relations to the kinship-based system in the form of joint-stock system to revise the defects of family enterprise management by making use of scientific and rational rules and regulations of modern enterprise. But no matter how generalizes the core management team members are, the core system is still based on the concept of family; it just requires employees to integrate into the enterprise and become one of the "pan-family" members in various forms, and takes family affection and interests as the key chain to maintain their relationships. In the process of the development of family enterprises, many enterprises have introduced professional managers to manage the enterprise, but because of an unsound credit system, as well as thousands of years of Chinese thought patterns, professional managers mode would be difficult to implement in the family businesses.

\subsection{Internal Capital-based Investment Model}

The collapse of the typical kinship and geoculture-based "mutual insurance debt" and "private lending" of Wenzhou enterprises makes the commercial contract, which is developed on the basis of self-restraint morality, of Wenzhou family enterprises suffer a fatal negation during the change, thus forcing the Wenzhou family enterprise to transform its credit system from "moral" restraint to "legal" restraint, and the traditional commercial culture begins to integrate with modern financial model with difficulty. However, China's capital market is in the period of system transition, at the same time, Wenzhou family enterprises lack experiences in using external capital on the one hand, while on the other hand, they lack of trust in financial capital. Parts of the family enterprises carry out financing through initial public offerings and transform to modern joint-stock enterprises by removing familization, but most of the Wenzhou family enterprises are still focused on effective utilization of internal capital, including try to break through by establishing family funds or investing in emerging industries with crowd funding.

\section{3 "Product Family-based" Industrial Internet Model}

Wenzhou enterprises have formed an efficient industrial cluster, which is a kind of enterprise cooperation model established on the basis of specialization under the background of competition, by taking product family as the core in the long-term development. Product family includes both the upstream and downstream of the whole industry chain for the production of certain product, and also includes all product categories required by certain brand. For example, Wenzhou shoes industry clusters includes all the supply enterprises clusters from raw materials to finished products, as well as all the processing plant clusters from sports shoes supply to shoes of various categories. In the internet era, Wenzhou's industrial networks and clusters must be combined with internet technology to create a flexible social platform, integrate into the global production and sales network and create a supply chain serving the brand based on all category mode of the product cluster. On the one hand, we can try to provide industrial chain platform support for social product design groups who are lack of production resources. On the other hand, it is necessary to pay close attention to the research and development of production technology and science technology, 
enhance product differentiation and brand advantages by creative designs and promote the upgrading of the industrial clusters to a higher value chain direction.

Any social phenomenon has its profound ideological origin, and the emergence, development and transformation of Wenzhou family enterprises are all based on their unique Chinese culture and ideology. Although many scholars believe that "familization removing" is the only way when they study on Wenzhou family enterprises, but in fact it cannot be achieve in the short term in the operational level; and on the other hand, "familization removing" won't necessarily change the crisis situation of Wenzhou family enterprises. In conclusion, Wenzhou family enterprises should translate their kinship-based "family concept" into corporate culture-based "new family concept" and focus on exploring its new values and models.

\section{References}

Chen shihui. (2014). From glory to sleepy - wenzhou family enterprise development inventory. Academic review, (01), 55-60

Dong Hongyi. (2012). Research on the financing of Wenzhou family enterprises based on the perspective of folk finance. The financial Times, (21), 231.

Liu maojuan. (2014). Family business research overview. Management manager, (01), 4.

Wei Jintong. (2010). Study on the crisis and countermeasures of intergenerational succession of wenzhou family enterprises. Special zone economy, (07), 58-59.

Wu Binde, Chen shihui, Dou Junsheng, Zhu Jianan. (2017). Dynamic and review of intergenerational entrepreneurship research of family enterprises. Chinese technology BBS, (03), 117-124.

Wu Lei, Bai Bingui. (2012). Analysis on the influence factors of succession training of family enterprises -- take wenzhou as an example. Journal of economic research, (1), 28-30+47.

XieShan. (2012). Analysis of family enterprises in Wenzhou. Shan Xi financial university.

Xin jinguo, Xu mingming, Pan Xiaofang. (2016). The empirical study on the influence of family values on the performance of wenzhou family enterprises. Productivity research, (01), 118-1

Zhang jin, Hu pan. (2015). The good man endures -- the secret of the long history of the east Asian family enterprise. Tsinghua management review, (12), 42-47. 